\title{
La Comisión Interamericana de Derechos Humanos: antecedentes, funciones y otros aspectos ${ }^{*}$
}

Este comentario, junto a los documentos que analiza, está disponible en www.anuariocdh.uchile.cl

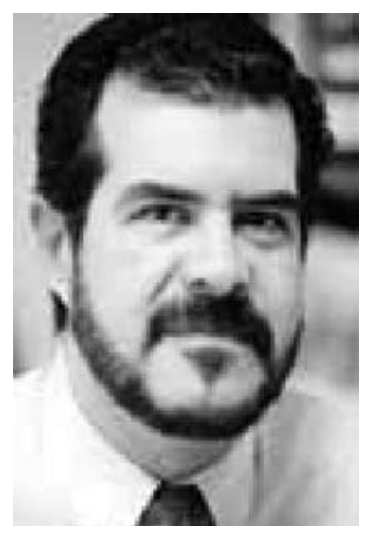

\section{Felipe González Morales}

Comisionado de la Comisión Interamericana de Derechos Humanos, donde también es Vicepresidente Segundo y Relator sobre Trabajadores Migratorios y sus Familias. Profesor de derecho internacional de los derechos humanos y derecho constitucional en la Universidad Diego Portales. Fundador y ex Director del Centro de Derechos Humanos en dicha Universidad y fundador y ex coordinador de una Red Latinoamericana de Clínicas Jurídicas de Derechos Humanos. Posee un Máster en Estudios Avanzados en derechos humanos en la Universidad Carlos III y un Máster en derecho internacional en American University, en cuya Academia de Derechos Humanos y Derecho Humanitario es Profesor desde 2001. Actualmente es Profesor Visitante en la Universidad Carlos III de Madrid. Anteriormente lo ha sido en la Universidad de Alcalá, la Universidad de Deusto, la Universidad Externado, la Universidad de Lund y la Universidad de Wisconsin. Trabajó para Global Rights, primero en Washington, D.C. y posteriormente en Santiago.

felipe.gonzalez@udp.cl

\section{RESUMEN}

A través del análisis de las principales funciones que desempeña la Comisión Interamericana de Derechos Humanos, el artículo analiza la evolución de la labor de este organismo en el contexto latinoamericano. Particularmente, compara el rol que la Comisión jugó en el contexto de las dictaduras militares con el que ha desempeñado durante los procesos de democratización y analiza cómo la Comisión se ha adaptado permanentemente a los nuevos contextos y necesidades del continente. Finalmente, el autor reflexiona sobre las prioridades y desafíos de la Comisión en el actual contexto político del Continente Americano.

\section{Introducción}

Este trabajo presenta una caracterización y análisis general de la Comisión Interamericana de Derechos Humanos (en adelante la CIDH o la Comisión), uno de los dos órganos de supervisión y vigilancia del Sistema Interamericano de protección de tales derechos (el otro es la Corte Interamericana de Derechos Humanos).

Para tales efectos, primeramente se revisa la evolución histórica de la Comisión, cuyo trabajo ha experimentado significativas transformaciones en función de la diversidad de contextos en los que ha debido operar. En segundo lugar se estudian sus principales funciones y el grado de impacto del ejercicio de éstas en el continente en materia de derechos humanos. Posteriormente el trabajo se detiene en algunos aspectos adicionales relevantes, tales como la cuestión de las prioridades de la Comisión y su autonomía.

\footnotetext{
* Las opiniones expresadas son del autor y no representan a las instituciones a las que pertenece.
} 


\section{Antecedentes históricos}

La Comisión fue creada durante la V Reunión de Consulta de Ministros de Asuntos Exteriores en el año $1959^{1}$ y su estatus fue posteriormente reforzado primero mediante la reforma a la Carta de la Organización de Estados Americanos (OEA) que introdujo el Protocolo de Buenos Aires en 1967 (convirtiéndose en un órgano principal y permanente de dicha organización), y luego por medio de la Convención Americana sobre Derechos Humanos (en adelante la Convención Americana). De este modo, la $\mathrm{CIDH}$ ha vivido un proceso de fortalecimiento y de progresiva ampliación de sus competencias, así como de su rol en el propio sistema interamericano de protección de derechos humanos.

La Comisión actúa en representación de todos los países miembros de la OEA. Está integrada por siete miembros independientes elegidos por la Asamblea General de la OEA que se desempeñan en forma personal sin representar a ningún país en particular ${ }^{2}$. Además, los comisionados no pueden participar en el debate o decisión sobre ninguna materia referida al Estado del cual sean nacionales. La Carta de la OEA, la Convención Americana sobre Derechos Humanos, el Estatuto de la Comisión y su Reglamento representan el marco jurídico que fija la organización y funciones de la CIDH. La Comisión tiene su sede en Washington, D.C.

La CIDH entró en funciones en 1960, una vez que se aprobó su Estatuto. Conforme con éste, adoptado por los órganos políticos de la OEA, la Comisión recibió una serie de atribuciones. Entre ellas se encontraban la preparación de estudios e informes que considerara necesarios para el desempeño de sus funciones; la promoción de los derechos humanos; la formulación de recomendaciones a los gobiernos en estas materias; la solicitud de información a los Estados acerca de las medidas adoptadas a nivel interno; y el servir como órgano de consulta de la OEA en materia de derechos humanos. Según el Estatuto, la Declaración Americana de Derechos y Deberes del Hombre sería el parámetro conforme al cual la Comisión evaluaría la situación interna de los Estados.

Otro aspecto interesante es que el Estatuto facultaba a la Comisión para trasladarse al territorio de cualquier Estado de la OEA previa autorización del mismo. Esta atribución en la práctica contribuiría muy pronto a darle visibilidad y reconocimiento a la Comisión a nivel de la población de los Estados, aumentando el impacto de sus actividades.

El Estatuto, en cambio, no se refería a la posibilidad de que la Comisión tramitara y decidiera denuncias sobre casos específicos de violaciones cometidas por los Estados. Sin embargo, desde su primer período de sesiones la Comisión puso énfasis en la importancia de llegar a poseer dicha función y así se lo hizo saber a los órganos políticos de la OEA. Así, ya en su primer período de sesiones, la Comisión le hizo saber a los organismos políticos de la OEA que sus facultades "no le permitirían realizar la misión que los pueblos de América pueden esperar de ella en defensa de los derechos humanos, pues ha considerado que su deber no debe limitarse a la simple promoción del respeto de esos derechos, sino que está obligada a cuidar de que ellos no sean violados" ${ }^{3}$.

Durante los años siguientes la Comisión plantearía reiteradamente esta enmienda, hasta obtener finalmente su aprobación. Cabe hacer notar que desde que entró en funciones la Comisión comenzó a recibir tales denuncias, sin que las declarara inadmisibles; éstas, en cambio, le servirían de base para la elaboración de informes sobre países, requiriendo en una serie de oportunidades

\footnotetext{
Mediante la Resolución Nº VIII de la V Reunión de Consulta de Ministros de Asuntos Exteriores, de 1959.

Artículos 34 al 36 de la Convención Americana.

OEA/Ser. L./V/II. 1 Doc. 32, 14 marzo 1961.
} 
informaciones de los Estados respectivos acerca de lo señalado en las denuncias. Así, la Comisión dejó constancia en el Acta de su primer período de sesiones que "acordó declarar que no estaba facultada para tomar ninguna decisión individual respecto a las comunicaciones o reclamaciones suscritas que reciba, pero que las conocería con el objeto de utilizarlas en la aplicación de los incisos b) y c) del [artículo 9 del] Estatuto"; además resolvió "[e]ncargar a su Secretaría que transmita las comunicaciones o reclamaciones recibidas a los Gobiernos de los Estados respectivamente interesados, cuando así lo hubiere acordado la Comisión durante los períodos de sesiones, o su Presidente durante los recesos de ellas" ${ }^{4}$.

Un elemento clave para que desde un comienzo la Comisión desempeñara un papel activo en la protección de los derechos humanos lo constituyó el que los comisionados servirían sus cargos a título personal y no como representantes de sus respectivos Estados. El hecho de que sus miembros operaran a título individual le dio a la Comisión Interamericana significativa agilidad y poder de decisión. Por ejemplo, en relación con la cuestión de las denuncias específicas, la Comisión de Derechos Humanos de la ONU durante más de 15 años las declaró inadmisibles, y recién avanzada la década de los sesenta instituyó un mecanismo que permitiría conocer de algunas de ellas, aunque sin establecer propiamente una tramitación específica de cada denuncia ${ }^{5}$. Esto contrasta con el criterio más flexible mostrado desde un principio por la Comisión Interamericana.

Como contrapartida, al ser la Comisión Interamericana un órgano de carácter técnico, no estaba diseñada para transformarse en un foro de discusión público, a la manera en que sí lo constituyó en la ONU primero la Comisión de Derechos Humanos de la ONU y más recientemente el Consejo de Derechos Humanos. Luego, la Comisión Interamericana debió descansar para tales efectos en los órganos políticos de la OEA, es decir, en el Consejo Permanente (que se reúne regularmente en Washington, D.C.) y en la Asamblea General de la organización.

Durante casi 20 años en un contexto de numerosos gobiernos dictatoriales y hasta la entrada en operaciones de la Corte Interamericana de Derechos Humanos en 1979, la Comisión fue el único mecanismo de protección de tales derechos en el sistema interamericano. En estas circunstancias, y dado que las dictaduras violaban los derechos humanos en gran escala y de manera sistemática, la Comisión utilizó como principal mecanismo para abordar tales violaciones la preparación y publicación de Informes sobre países. En ellos se revisaba la situación general de los derechos humanos en determinados países, con especial atención a los atentados contra el derecho a la vida, a la práctica de la tortura y la detención y prisión arbitraria de personas. Durante sus primeros años de funcionamiento la Comisión elaboró Informes sobre Cuba, Ecuador, Guatemala, Haití, Honduras, Nicaragua, Paraguay y República Dominicana. Cabe mencionar que Cuba fue suspendida de sus derechos como miembro de la OEA en 1962, sin perjuicio de lo cual la CIDH consideró que mantenía competencia respecto de dicho país al no haber Cuba denunciado la Carta de la OEA.

4 Ídem. Los mencionados incisos del Estatuto de la época establecían lo siguiente: b) Formular recomendaciones en caso de que lo estime conveniente, a los Gobiernos de los Estados miembros en general, para que adopten medidas progresivas en favor de los derechos humanos dentro de sus legislaciones internas y tomen, de acuerdo con sus preceptos constitucionales, medidas apropiadas para fomentar la fiel observancia de esos derechos; c) Preparar los estudios o informes que considere convenientes en el desempeño de sus funciones.

5 Me refiero a los procedimientos instituidos primero bajo la Resolución 1237 de Ecosoc y luego conforme a la 1503 del mismo órgano. Este procedimiento ha sido asumido por el Consejo de Derechos Humanos, que reemplazó en 2006 a la antigua Comisión. Conforme a este procedimiento, se investigan los hechos alegados solo en cuanto se inscriban dentro de un cuadro de violaciones masivas y sistemáticas, pero sin que ello pueda conducir a una decisión específica sobre el caso, sino solo como un elemento que podría ser incorporado a una resolución general sobre el país de que se trate. 
En 1966 la Comisión adquirió también la función de tramitar y decidir acerca de denuncias en materia de derechos humanos. La importancia de este mecanismo radica, por una parte, y como es obvio, en la posibilidad de levantar públicamente una violación específica y procurar alcanzar una solución a ella; por otra, su presencia es central desde el punto de vista del desarrollo del derecho internacional de los derechos humanos, ya que significa en la práctica y de manera concreta hacer efectivo el carácter de sujeto internacional que la persona humana posee conforme a dicha normativa.

No obstante, en el período 1960-1990 la publicación de Informes sobre países continuó siendo la tarea principal de la Comisión. Había dos razones básicas para ello. En primer lugar, muchos de los Estados en contra de los cuales se interponían denuncias individuales no participaban en la tramitación de los casos, es decir, no contestaban las denuncias y no enviaban respuesta alguna a los requerimientos de la Comisión, o bien solo lo hacían de manera sumaria, sin entrar al fondo de las alegaciones ni menos a presentar pruebas de descargo. En este contexto, la Comisión incluyó en su Reglamento una disposición conforme a la cual se presumen verdaderas las alegaciones de los denunciantes en la medida en que ellas no aparezcan controvertidas por el Estado o por otras fuentes. Por esta vía, una gran cantidad de denuncias individuales fueron acogidas por la $\mathrm{CIDH}$ en el período indicado.

En segundo lugar, y dado que la Comisión lidiaba fundamentalmente con violaciones masivas y sistemáticas, esto es, que obedecían a un plan deliberado de ciertos Estados, la solución de casos individuales, ya fuese que el Estado hubiera participado o no en la tramitación ante la $\mathrm{CIDH}$, resultaba notoriamente insuficiente. Si de lo que se trataba era de acometer cientos y en ocasiones miles de violaciones cometidas en un corto tiempo por un mismo Estado, resultaba imposible que la resolución de casos específicos pudiera ser efectiva para transformar la situación general. Tratándose de ciertos casos paradigmáticos, estos pueden haber sido importantes, pero de ningún modo suficientes.

En la elaboración de los Informes sobre países, la Comisión recurrió desde un comienzo a las visitas in loco, es decir, visitas al lugar donde las presuntas violaciones habían ocurrido. Como observáramos anteriormente, el Estatuto de la Comisión la facultaba para ello, siempre que contara con el consentimiento del Estado. Desde un principio la Comisión ha sido activa en solicitarle a los Estados tales visitas, reiterando sus solicitudes cuando ello ha sido necesario.

Cabe destacar, por último, que la competencia de la Comisión no se ve limitada a los Estados partes de la Convención Americana sino que abarca asimismo al resto de Estados miembros de la OEA, ya que mantiene facultades anteriores a la entrada en vigor de dicho instrumento. En este sentido, la Comisión está facultada a procesar denuncias relativas a Estados partes de la OEA que no son parte de la Convención ${ }^{6}$.

\section{Funciones de la CIDH}

Aunque la Comisión posee una amplia variedad de funciones, para efectos de su exposición sistematizada las analizaremos en los siguientes términos:

- Preparar Informes sobre países;

- Realizar visitas in loco;

6 Conforme al Estatuto de la Comisión, ésta tiene atribuciones respecto de: (i) los Estados miembros de la OEA (artículo 18); (ii) los Estados partes en la Convención Americana (artículo 19); (iii) los Estados miembros de la OEA que no son parte en la Convención Americana (artículo 20). 
- Desarrollar un trabajo especializado en ciertas áreas temáticas, a través de Relatorías y otros mecanismos;

- Llevar a cabo labores de promoción y otras iniciativas;

- Conocer y resolver denuncias en casos específicos.

\section{a. Informes sobre países}

La Comisión prepara y publica los Informes sobre países de dos maneras. La primera consiste en un informe dedicado exclusivamente a un país. Éste puede llegar a ser muy extenso (más de 100 páginas) y usualmente es precedido por una visita al Estado respectivo, salvo que éste no autorice a la CIDH para ingresar a su territorio. La segunda es un informe más breve que se incorpora en el Informe Anual de la Comisión. Estos últimos pueden o no ser precedidos de una visita de la Comisión o de algunos de sus miembros al país.

Durante las primeras décadas de funcionamiento de la Comisión, los Informes sobre Países se concentraron prácticamente de manera exclusiva en violaciones a los derechos civiles y políticos. Esto se explica porque eran estos derechos (por ejemplo, el derecho a la vida, el derecho a no ser torturado, el derecho a no ser detenido arbitrariamente, etc.) los que resultaban violados a gran escala por los regímenes dictatoriales. Posteriormente se ha asentado la práctica de que estos Informes sobre Países también se refieran a Derechos Económicos, Sociales y Culturales (DESC). Además, ellos han incorporado una perspectiva de género para analizar las violaciones, y se refieren a otros colectivos vulnerables, tales como pueblos indígenas, poblaciones afrodescendientes $\mathrm{u}$ otros que existan en el respectivo Estado.

La elaboración y publicación de Informes sobre Países constituyó prácticamente la única tarea que la Comisión llevó a cabo en sus primeros años de funcionamiento. Incluso cuando la CIDH adquirió competencia para conocer y resolver casos específicos, su labor central continuó siendo la preparación de tales Informes. Esta fue la situación hasta, aproximadamente, 1990.

El impacto de los Informes sobre Países se ha visto favorecido además porque para su preparación la Comisión ha recurrido desde un comienzo a las visitas in loco. Este mecanismo ha probado ser crucial para realzar el perfil de la Comisión, puesto que es justamente durante tales visitas que su labor alcanza su mayor cobertura de prensa, además de atraer la atención de las autoridades estatales, de las víctimas y de otras personas e instituciones interesadas en las condiciones de los derechos humanos en el país sede de la visita. De hecho, la Comisión usualmente recibe nuevas denuncias durante estas visitas. Incluso en los casos en que la Comisión no es autorizada para visitar un país, el solo hecho de la falta de autorización tiende a producir interés en la opinión pública y coloca a las autoridades estatales en la necesidad de ofrecer explicaciones por su rechazo.

Con motivo de los procesos de transición a la democracia en casi la totalidad de los Estados de la OEA, la preparación y publicación de Informes sobre Países por parte de la Comisión fue replanteada. Algunos Estados comenzaron a sostener que el Sistema Interamericano de Derechos Humanos en general y la Comisión Interamericana de Derechos Humanos en especial habían sido creados en un contexto en el que la situación de los derechos humanos en el Continente difería sustancialmente de la de los noventa. El antiguo contexto correspondería a uno en el que predominaban dictaduras que cometían violaciones masivas y sistemáticas de los derechos humanos, mientras que el existente a partir de los noventa estaría caracterizado por la presencia -como regla general- de gobiernos democráticamente elegidos, supuestamente preocupados ellos mismos por la protección de tales derechos. Estas diferencias -sostenía este grupo de Estados- ponían en evidencia lo inadecuado de las funciones y formas de operar del Sistema -especialmente de la 
Comisión- respecto de las necesidades del nuevo contexto. Siguiendo con su argumento, planteaban entonces que la CIDH debería concentrarse en sus labores de promoción de los derechos humanos, es decir, en difundir el conocimiento acerca de tales derechos y en realizar actividades de educación en la materia. El rol de protección de los derechos humanos debería, en consecuencia, quedar entregado básicamente a una tarea interna de los Estados, siendo necesario reducir el papel de la Comisión al respecto o, como se sugería a veces entre líneas, incluso eliminarlo ${ }^{7}$.

Una propuesta central en este sentido consistía en poner fin a los Informes sobre países de la Comisión Interamericana. Estos Informes, según los países que propugnaban por su abolición, habían tenido sentido en la época de las dictaduras, pero supuestamente ya no lo tenían en el nuevo contexto. Una propuesta subsidiaria a la anterior consistió en terminar con la facultad de la Comisión de decidir qué Estados eran merecedores de un Informe, y entregar esta determinación a los órganos políticos de la OEA. Se trató de una idea que los Estados a los que se refieren los Informes habían planteando desde que la Comisión iniciara esta modalidad de trabajo.

Lo cierto es que si se contrasta la situación entre el Sistema Interamericano y el de las Naciones Unidas, donde la selección de los países que se considera requieren de un Relator Especial ha sido tradicionalmente realizada por órganos integrados por Estados, se apreciará que el mecanismo establecido en el Sistema Interamericano es muy superior.

En estas circunstancias la Comisión explicitó en 1997 una serie de criterios -vigentes actualmentepara la determinación de los países que se hacen merecedores de Informes ${ }^{8}$ :

- Cuando se trata de Estados regidos por gobiernos que no han llegado al poder mediante elecciones populares, por el voto secreto, genuino, periódico y libre, según normas internacionalmente aceptadas;

- Cuando se trata de Estados donde el libre ejercicio de los derechos consignados en la Convención Americana o la Declaración Americana ha sido en efecto suspendido, en su totalidad o en parte, en virtud de la imposición de medidas excepcionales, tales como el estado de emergencia, el estado de sitio, prontas medidas de seguridad y demás;

- Cuando existen pruebas fehacientes de que un Estado comete violaciones masivas y graves de los derechos humanos garantizados en la Convención Americana, Declaración Americana y demás instrumentos de derechos humanos aplicables, siendo motivo de especial preocupación en este caso las violaciones de los derechos que no pueden suspenderse, como las ejecuciones extrajudiciales, la tortura y la desaparición forzada;

- Cuando se trata de Estados que se encuentran en un proceso de transición de cualquiera de las tres situaciones arriba mencionadas;

- Cuando existan situaciones coyunturales o estructurales que afecten seria y gravemente los derechos humanos, incluyendo situaciones graves de violencia, graves crisis institucionales, procesos de reforma institucional con graves incidencias negativas para los derechos humanos,

Sobre este debate, consúltese FARER T. The future of the Inter-American Commission on Human Rights: Promotion versus Exposure. En: MÉNDEZ J. Y COX F. (eds.). El Futuro del Sistema Interamericano de Protección de los Derechos Humanos. Instituto Interamericano de Derechos Humanos, San José, Costa Rica, 1998, pp. 515-536; GONZÁLEZ F. Informes sobre Países, Promoción y Protección. En: MÉNDEZ J. y COX F. (cit.), pp. 493-513.

8 Estos criterios aparecen recogidos en la Introducción de Capítulo IV del Informe Anual, que se refiere justamente a los Informes sobre Países. 
u omisiones graves en la adopción de medidas necesarias para hacer efectivos los derechos humanos.

Además, la Comisión adoptó como una práctica -que posteriormente incluyó en su Reglamento-9 el enviar al Estado sobre el cual trata el Informe una copia del Proyecto del mismo. De este modo, el Estado puede hacer las observaciones que le parezcan pertinentes. Posteriormente la Comisión elabora una versión final del Informe.

La elaboración de Informes sobre Países por parte de la Comisión continúa teniendo pleno sentido en ciertas circunstancias y por eso este papel ha sido reafirmado por la propia CIDH. Los Informes cubren necesidades que la tramitación de casos específicos individuales no satisface por sí sola.

Cabe añadir que el sistema de Informes sobre Países de la Comisión Interamericana de Derechos Humanos y los que prepara la ONU son complementarios, sin que exista un problema de duplicidad por el hecho de que diferentes órganos internacionales elaboren informes paralelamente. Muy por el contrario, las iniciativas paralelas contribuyen a potenciar el monitoreo. Incluso, cuando tanto la CIDH como órganos de la ONU preparan Informes sobre un mismo país, dichos organismos se coordinan e informan mutuamente, lo que redunda en Informes más completos, acuciosos y de mayor impacto.

\section{b. Visitas in loco}

Entre las atribuciones más importantes que tiene la Comisión Interamericana está la de practicar visitas in loco (en el lugar) a los países. Ellas han contribuido a dar visibilidad a la Comisión en los países americanos, así como a fortalecer el impacto de su trabajo. Las visitas consisten en delegaciones de los miembros de la Comisión y de los abogados que los apoyan que acuden a los diferentes países de la OEA y mantienen reuniones con autoridades y miembros de la sociedad civil, además de trasladarse a distintos puntos del país para tomar conocimiento acerca de la situación en materia de derechos humanos.

Las visitas pueden tener diferentes propósitos. Ellas pueden estar destinadas a estudiar la situación general de los derechos humanos en el país que se visita. También es posible que se realice para verificar la situación de un derecho específico o situación particular, como, por ejemplo, para estudiar la situación de los pueblos indígenas en un país o sus condiciones carcelarias. Asimismo la visita puede estar relacionada con la necesidad de obtener información respecto de una o más denuncias pendientes ante la Comisión.

Sin perjuicio de lo anterior, las observaciones in loco cumplen funciones y objetivos que van mucho más allá de la verificación de hechos. La mera presencia de la Comisión en un país genera un debate sobre la situación de los derechos humanos y su visita usualmente se difunde a través de los medios de comunicación. Todo ello permite conocer y acceder al Sistema Interamericano a un mayor número de personas. Una visita de la Comisión también cumple funciones de prevención de violaciones futuras, dado que en muchas oportunidades ella, al dar a conocer la situación de los derechos humanos en un país, contribuye a que la opinión pública tanto a nivel nacional como internacional se informe, exija el respeto de los derechos y ejerza una mayor fiscalización sobre las autoridades estatales. Por último, las visitas también cumplen una labor educativa y de promoción de los derechos humanos.

9 Artículos 57.2 y 58 del Reglamento. 
La decisión de realizar una visita in loco. Para que la Comisión pueda realizar una visita siempre se requiere de una autorización del Gobierno. La forma en que se consigue dicha autorización varía de caso en caso. Una visita se puede dar por una invitación motu proprio del Gobierno, aunque casi siempre es la propia Comisión la que le solicita al Gobierno que la invite.

Entre las razones que llevan a la Comisión a tomar la decisión de realizar una visita in loco en un país está la acumulación de denuncias por violaciones de derechos humanos, especialmente cuando de ellas se pueda inferir un cuadro sistemático de violaciones graves. La Comisión también puede solicitar autorización para realizar una visita in loco con el propósito de estudiar el progreso que se haya dado en el área de los derechos humanos a partir de sus últimas observaciones en el país.

Las actividades de la Comisión durante una visita. A lo largo de su historia, la Comisión ha creado una práctica respecto de las actividades que lleva a cabo en los países que visita. La duración de una visita depende del tamaño del país, de la gravedad de la situación y de la agenda de trabajo que se tenga. Por lo general, las visitas se extienden entre cinco y diez días. La Comisión siempre se reúne con autoridades públicas de los distintos poderes del Estado. Usualmente se entrevista con el Presidente de la República o quien sea el Jefe del Poder Ejecutivo, con miembros del Congreso y del Poder Judicial. También suele reunirse con Ministros relevantes en materia de derechos humanos, tales como el de Interior (Gobernación), el de Defensa, Justicia, Relaciones Exteriores, etc. En muchos casos, la CIDH solicita reuniones especiales como otras personas relevantes tales como el Jefe de la Policía, el Defensor del Pueblo, el Fiscal General, la Junta Nacional Electoral y el organismo encargado de las cuestiones indígenas, entre otros. En último término, estas reuniones dependerán de los temas que preocupen y motiven la visita de la Comisión.

Por lo general la Comisión visita cárceles, cuarteles militares, tribunales, etc. En ocasiones visita campos de refugiados. Por lo general, la Comisión visita la capital del país y algunas regiones del país. En muchas ocasiones ha visitado comunidades indígenas.

La Comisión se reúne además con distintos estamentos de la sociedad civil. Por ejemplo, con organismos no-gubernamentales, periodistas y sindicatos. También se suele encontrar con partidos políticos, tanto oficialistas como de oposición; con líderes indígenas o de comunidades afrodescendientes.

Todas las entrevistas que sostiene y la documentación recolecta le permiten a la Comisión formarse una opinión general sobre lo que sucede en el país. Lo más importante de esta práctica de la Comisión es que ella no solamente se reúne con las autoridades. Esto facilita que reciba visiones, opiniones e información de diversas fuentes y no una información que recoja únicamente el punto de vista oficial. Con ello se fortalece enormemente la imparcialidad de las conclusiones a las que arriba la Comisión.

Para poder desempeñar libremente sus funciones la $\mathrm{CIDH}$ requiere de una serie de garantías de parte del Gobierno. En particular, el Gobierno debe conceder a la Comisión todas las facilidades necesarias para llevar a cabo su tarea. Entre los aspectos más relevantes se cuenta el que el Gobierno deberá comprometerse a no tomar represalias de ningún orden en contra de las personas o entidades que cooperaron con la Comisión proporcionándole informaciones o testimonios. El cumplimiento de esta obligación del Gobierno es fundamental para el éxito de una visita.

El Informe de la Comisión como consecuencia de una visita. La Comisión en la mayoría de los casos emite un informe luego de realizar una visita in loco. Dicho informe no solamente relatará las actividades que realizó sino que principalmente describirá la situación que encontró, la analizará a la luz de las obligaciones internacionales del país y emitirá recomendaciones al 
Gobierno para mejorar la situación de los derechos humanos en el país. Un anticipo de lo que contendrá dicho informe se puede encontrar en el comunicado de prensa que la Comisión emite al final de una visita.

\section{c. Trabajo temático especializado a través de relatorías y otros mecanismos}

Desde la década de los noventa la Comisión ha venido desarrollando una serie de iniciativas de carácter temático, es decir, referidas a algún derecho o derechos en particular o a determinados colectivos vulnerables. Esto resulta complementario a los Informes sobre Países, que dicen relación con la situación general de los derechos humanos en un Estado específico. En este sentido, han sido elaborados Informes sobre temas tales como la situación de los derechos humanos de las mujeres, de las personas privadas de libertad, las condiciones de los trabajadores migratorios y sus familias, etc.

Este trabajo se ha venido desarrollando especialmente a través de las relatorías temáticas que la Comisión ha creado en los últimos 15 años. Como es bien sabido, en Naciones Unidas las relatorías juegan un papel importante en materia de derechos humanos. No obstante, en la CIDH estas relatorías temáticas en general poseen un perfil considerablemente más bajo que en el Sistema de Naciones Unidas. La razón de ello es que los recursos disponibles al respecto son muy limitados en la CIDH. Salvo en el caso de la Relatoría sobre Libertad de Expresión, son los propios miembros de la Comisión quienes se han desempeñado como relatores. No siendo los miembros de la Comisión funcionarios a tiempo completo, deben realizar estas tareas en añadidura a muchas otras. De allí que su papel se haya circunscrito generalmente a la elaboración y difusión de algunos estudios, sin que ellos hayan alcanzado el mismo impacto que los Informes sobre Países.

La situación ha sido diferente en el caso de la Relatoría para la Libertad de Expresión -creada en 1998-, ya que al contar ésta con recursos propios, está encabezada por un Relator a tiempo completo y posee su propio "staff". Esto ha llevado a que esta Relatoría desarrolle actividades de mayor envergadura que las demás relatorías. Esto tiene consecuencias en varios ámbitos. En primer lugar, la Relatoría prepara y publica anualmente un Informe sobre la situación de la libertad de expresión en el continente. Este Informe es publicado como un volumen adicional al Informe Anual de la Comisión Interamericana de Derechos Humanos. En segundo lugar, la Relatoría da seguimiento a los casos en materia de libertad de expresión que se hallan en curso en el Sistema Interamericano. Esto no significa que las denuncias en la materia deban ser presentadas ante el Relator: ellas deben continuar siendo enviadas al Secretario Ejecutivo de la Comisión. En tercer lugar, la Relatoría efectúa un seguimiento de atentados contra la libertad de expresión a nivel interno de los Estados, aun cuando tales violaciones no hayan Ilegado ante el Sistema Interamericano. Al respecto, el papel de las organizaciones no-gubernamentales es crucial, ya que usualmente serán éstas las que pongan en conocimiento y llamen la atención de la Relatoría acerca de tales hechos. La Relatoría puede emitir comunicados de prensa y/o tomar contacto con autoridades del respectivo país para superar las violaciones ocurridas. Finalmente, la Relatoría forma parte de la delegación de la Comisión durante las visitas in loco, además de efectuar sus propias visitas. En general, por tratarse de un órgano unipersonal, resulta más expedito preparar una visita de la Relatoría que de la Comisión como conjunto. El acompañamiento de la Relatoría en las visitas in loco de la $\mathrm{CIDH}$ se ha convertido en una práctica habitual, y constituye un refuerzo en las iniciativas de la Comisión en lo que se refiere a la protección de la libertad de expresión.

Las demás relatorías son encabezadas por un Comisionado o Comisionada, que asume esta labor entre otras diversas que realiza para la CIDH. No obstante, en los últimos años, algunas de estas relatorías han contratado algún personal propio, generalmente una sola persona. Ellas son la Relatoría sobre Derechos de la Mujer, la de Personas Privadas de Libertad, la de Pueblos 
Indígenas, la de la Niñez, la de Trabajadores Migratorios y su Familias y -la más reciente- la de Afrodescendientes.

Con mayor o menor intensidad, dependiendo en buena medida de los recursos disponibles, estas relatorías efectúan estudios, realizan visitas a algunos países, efectúan un acompañamiento de la tramitación de denuncias y de medidas cautelares, y participan en la elaboración de algunos instrumentos internacionales.

Los estudios emanados de estas relatorías a veces se publican como volúmenes especiales ${ }^{10}$ y en otras ocasiones forman parte del Informe Anual de la Comisión ${ }^{11}$.

Respecto de la elaboración de estándares, la Relatoría sobre Personas Privadas de Libertad concluyó a principios de 2008 un conjunto de Buenas Prácticas en Materia de Personas Privadas de Libertad, el que fue aprobado por el pleno de la Comisión. En el caso de la Relatoría sobre Pueblos Indígenas, ha acompañado el proceso de preparación de una Declaración Interamericana en la materia. La Relatoría sobre Afrodescendientes participa en el proceso de elaboración de una Convención Interamericana contra el Racismo, la Xenofobia y la Intolerancia.

Otro órgano dependiente de la CIDH en cuestiones temáticas es la Unidad sobre Defensores de Derechos Humanos. Esta Unidad fue creada a fines de la década pasada a instancias de organizaciones no-gubernamentales, con el propósito de fortalecer los mecanismos de protección de tales defensores y llamar la atención de los Estados respecto de las violaciones a los derechos humanos de que son objeto. Cabe resaltar el efecto multiplicador que posee la protección de los defensores, ya que por su intermedio se está garantizando además que se protejan los derechos de otras personas, a los cuales dichos defensores defienden o representan. La Unidad publicó en 2006, como un volumen especial, un "Informe sobre la situación de las defensoras y defensores de los derechos humanos en las Américas".

Los temas que aborda la Comisión no se limitan a los anteriores ya que, dependiendo de las circunstancias, también puede efectuar estudios en otras áreas. Por ejemplo, luego de los atentados contra las Torres Gemelas la CIDH preparó un extenso estudio temático sobre el terrorismo y los derechos humanos, mostrando cómo la lucha contra el primero debe ceñirse a los estándares internacionales de derechos humanos. Más recientemente, se han publicado, entre otros, un Informe titulado "El acceso a la justicia como garantía de los derechos económicos, sociales y culturales" y otro denominado "Lineamientos para la Elaboración de indicadores de progreso en materia de derechos económicos, sociales y culturales".

\section{d. Labores de promoción de los derechos humanos y otras iniciativas}

Además de las funciones antes descritas, la CIDH desempeña actividades de promoción de los derechos humanos, así como otras tareas.

Labores de promoción. Estas labores, que la CIDH emprende a través de seminarios, publicaciones, pasantías y otros medios, se han referido básicamente a tres grandes ámbitos: la difusión de los derechos humanos en general, la promoción del propio Sistema Interamericano de Derechos Humanos y la educación acerca de la necesidad de incorporar los derechos humanos en el orden jurídico interno.

10 Entre los más recientes se cuenta el publicado por la Relatoría sobre Derechos de la Mujer en 2007, titulado "Acceso a la Justicia de Mujeres Víctimas de Violencia en las Américas".

11 Por ejemplo, la Relatoría sobre Trabajadores Migratorios y sus Familias ha publicado una serie de informes incorporados en el Informe Anual de la Comisión. 
El primero de los aspectos mencionados se refiere a las tareas llevadas a cabo por la Comisión respecto a la necesidad de que la población de los países del continente tome conciencia acerca de sus propios derechos. Por este camino se pretende que los derechos humanos no sean sólo en una consagración jurídico-normativa, sino que se hagan realidad en la cultura de las sociedades americanas. Esto está estrechamente conectado con la eficacia de estos derechos, ya que si las víctimas de las violaciones no tienen cabal conciencia de ellos, se favorece la impunidad. Esto también se vincula con el afianzamiento de sistemas democráticos genuinos; en efecto, la conciencia acerca de sus derechos es un factor dinamizador de la participación y del control de la gestión pública por la ciudadanía.

El segundo ámbito apunta a las labores de promoción que la Comisión ha emprendido en orden a hacer saber a los habitantes del hemisferio acerca de la existencia del Sistema Interamericano de Derechos Humanos, así como los pasos básicos que ellos deben dar para interponer denuncias ante la Comisión. Dado que la Comisión, salvo situaciones muy excepcionales, carece de los medios para llevar a cabo investigaciones motu proprio, depende en una importante medida de la iniciativa de la sociedad civil para conocer de las violaciones a los derechos humanos. Gran parte de las actividades de promoción de la $\mathrm{CIDH}$ se han concentrado precisamente en este ámbito, por el interés directo que la Comisión tiene en que la sociedad civil se mantenga bien informada a este respecto y que sepa a quién y cómo acudir en caso de una violación a sus derechos.

El tercer y último ámbito está referido a las labores de promoción destinadas a resaltar la necesidad de incorporar los derechos humanos en el orden jurídico interno. Los órganos internacionales cumplen un rol subsidiario, en el entendido de que, en condiciones normales, los órganos internos están en posición de resolver de manera más pronta y eficaz las situaciones de vulneración de derechos. Éste es un aspecto en el que también la Comisión ha puesto énfasis, siendo como es ella la primera interesada en que sólo en casos de real necesidad se utilice el Sistema Interamericano.

Como se aprecia, la CIDH cumple labores importantes de promoción. Sin embargo, estas labores no pueden ser entendidas sino como un complemento a las tareas centrales de la Comisión: las labores de protección. Existen numerosos organismos académicos, no-gubernamentales y estatales que realizan actividades de promoción de los derechos humanos y, por lo mismo, el papel de la $\mathrm{CIDH}$ al respecto no es en absoluto único. En cambio, como órgano de protección de tales derechos, el papel de la Comisión resulta insustituible, ya que ninguna otra entidad (ni siquiera la Corte Interamericana de Derechos Humanos, que no posee las mismas funciones que la Comisión) tiene el mismo rol que la $\mathrm{CIDH}$.

Por eso la Comisión ha continuado manteniendo como eje principal de su acción las labores de protección, atribuyendo a la promoción un carácter complementario.

Otras actividades de la CIDH. La Comisión Interamericana posee un mandato muy amplio, por lo que cual se encuentra facultada para llevar a cabo un amplio y diverso rango de iniciativas. Entre éstas resaltan la participación de este organismo en la preparación de tratados y declaraciones sobre derechos humanos y el ejercicio de una función consultiva en la OEA.

En relación con el primero de estos aspectos, en la elaboración de estos instrumentos interamericanos de derechos humanos, intervienen tanto los órganos políticos de la OEA como la Comisión. En el caso de algunos de tales tratados y declaraciones, la $\mathrm{CIDH}$ ha tenido un papel muy importante; otras veces, en cambio, los órganos políticos de la OEA no han seguido de cerca los planteamientos de la Comisión.

En cuanto al segundo aspecto, la Comisión está facultada para recibir consultas por parte de los Estados de la OEA sobre cuestiones relacionadas con los derechos humanos, pudiendo prestarles 
su asesoramiento al respecto. En los últimos años ha emitido pronunciamientos acerca de las cuotas para mujeres de modo de garantizar su representación en los sistemas políticos y preparó un estudio sobre las acciones afirmativas para afrodescendientes, entre otras iniciativas.

\section{e. Tramitación de casos específicos}

La Comisión es competente para recibir y procesar denuncias sobre casos específicos en los cuales se alegan violaciones a los derechos humanos ${ }^{12}$ formuladas por cualquier persona, grupos de personas u organizaciones no gubernamentales (ONGs) reconocidas por cualquier Estado miembro de la OEA. También puede interponer denuncias un Estado contra otro, pero ello sólo ha ocurrido en una oportunidad, cuando en 2006 Nicaragua presentó una denuncia en contra de Costa Rica ${ }^{13}$.

Con la presentación de una denuncia, la Comisión da inicio a un proceso semijudicial de investigación. En esta tarea, la Comisión tiene también el rol de procurar que se alcance una solución amistosa entre los denunciantes y los representantes del Estado en términos acordes con el marco normativo del Derecho Internacional y evitar así acudir a la Corte Interamericana. Sólo en el caso de no alcanzarse un acuerdo amistoso entre las partes y de que existan elementos suficientes para concluir que el Estado en cuestión vulneró derechos reconocidos en la Convención Americana, la Comisión procederá a decidir el fondo del caso y eventualmente enviarlo a la Corte. La Comisión es un primer filtro que asegura que sólo lleguen denuncias fundadas a la Corte y sobre las que las partes no han logrado un acuerdo.

Un punto importante que refleja las características sociales y políticas de la región es que las denuncias, de acuerdo al artículo 44 de la Convención Americana, pueden ser presentadas por cualquier persona u ONGs, es decir, la petición no está limitada a la víctima ${ }^{14}$ ni será necesario contar con su consentimiento. En este sentido, las víctimas de violaciones de derechos humanos no son las únicas legitimadas para instar a la Comisión, pudiendo hacerlo terceros e incluso instituciones.

Hay que tener en cuenta que un gran número de denuncias han estado relacionadas a desapariciones forzadas, ejecuciones extrajudiciales, masacres y torturas, por lo que con buen criterio se acepta que ellas puedan ser presentadas por familiares, así como organizaciones de defensa de derechos humanos ${ }^{15}$. Asimismo, el sistema interamericano no prevé un servicio de asesoría o patrocinio jurídico gratuito para las víctimas, por lo que el rol de las organizaciones de defensa y promoción de derechos humanos en la región ha sido fundamental.

La tramitación de las peticiones individuales por la Comisión sigue un procedimiento que se divide en tres grandes etapas: (i) trámite inicial y procedimiento de admisibilidad; (ii) tramitación en el fondo y la decisión sobre el fondo, (iii) y eventual sometimiento del caso a la Corte

12 Artículos 44 al 51 de la Convención Americana sobre Derechos Humanos.

13 Dicha denuncia fue declarada inadmisible por la Comisión, al considerarla manifiestamente infundada. Véase, Comisión Interamericana de Derechos Humanos, Informe № 11/07, Caso Interestatal 01/06, Nicaragua c. Costa Rica, 8 de marzo de 2007.

14 Es necesario señalar que el sistema interamericano, a diferencia del sistema europeo, no prevé la posibilidad de brindar ayuda financiera a las víctimas. Sobre este punto se vuelve más adelante.

15 A diferencia de la práctica en el sistema europeo de derechos humanos, ya que el Convenio Europeo de Derechos Humanos en su artículo 25.1 establece que las denuncias han de ser formuladas por aquellas personas físicas, Organizaciones No Gubernamentales o grupos de particulares que se consideren víctimas de una violación de sus derechos reconocidos en el Convenio o sus Protocolos. Se formula un concepto de víctima restringido en el sentido de que sólo podrán presentar denuncias las consideradas víctimas directas. 
Interamericana de Derechos Humanos. A continuación se sintetizan los principales aspectos de cada una de ellas.

\section{i. Trámite inicial y procedimiento de admisibilidad}

La Secretaría Ejecutiva de la Comisión será la encargada de recibir y registrar la petición, registrar la fecha de recepción y acusar recibo al peticionario ${ }^{16}$. Deberá llevar a cabo la revisión inicial de la petición verificando si reúne los requisitos exigidos por el artículo 28 del Reglamento de la Comisión. Si no los reúne, podrá solicitar al peticionario que complete los requisitos ${ }^{17}$. Si éste no cumpliera con la solicitud, la Comisión procedería a archivar la petición.

Entre los requisitos que resaltaremos se halla la necesidad de presentar la petición dentro de los seis meses de notificada la resolución judicial que agota los mecanismos internos, el que no se encuentre pendiente de resolución la materia de la petición en otro procedimiento internacional, el agotamiento de los recursos internos y la caracterización de hechos que tiendan a configurar una violación de los derechos humanos. A continuación nos detendremos en los dos últimos.

La exigencia de agotar los recursos internos es un requisito de admisibilidad habitual en los instrumentos internacionales de protección de derechos humanos que establecen un procedimiento o mecanismo contencioso de protección de tales derechos. Esta regla se basa en la concepción de la protección internacional de los derechos humanos como subsidiaria a la jurisdicción interna de los Estados en los supuestos en que existe una persona indefensa frente al Estado que menoscaba o viola sus derechos. Esto es coherente con el objetivo de los instrumentos internacionales de derechos humanos de fortalecer los mecanismos de protección en el derecho interno de los Estados, los cuales poseen el deber de establecer los recursos internos idóneos para la protección de dichos derechos.

El requisito de carácter regla general de agotar los recursos internos contempla excepciones. Así, los artículos 46 de la Convención Americana y 31 y 32 del Reglamento de la Comisión establecen que el mismo no será exigido (i) si no existe en el sistema interno un debido proceso legal para la protección de derechos que hayan sido violados, (ii) si no se ha permitido al presunto lesionado en sus derechos el acceso a los recursos de la jurisdicción interna o se le ha impedido agotarlos, (iii) así como cuando exista un retardo injustificado en la decisión sobre los mencionados recursos.

La evolución que ha experimentado la aplicación de la regla del agotamiento de los recursos internos, debe resaltarse. Históricamente en el grueso de las denuncias de violaciones masivas y sistemáticas, los recursos internos eran generalmente ineficaces para solucionar la violación, dado que en el contexto de dictaduras había problemas estructurales de falta de independencia de los sistemas judiciales para encarar casos de derechos humanos, sin que existieran elementos básicos de un debido proceso legal, además de fuertes y frecuentes presiones sobre los jueces y abogados en este tipo de casos. En este contexto la regla general de agotamiento de los recursos internos de general solo tenía el nombre, ya que en la práctica de la Comisión regularmente se aplicaban las excepciones a dicha regla ${ }^{18}$.

Con el advenimiento de las transiciones a la democracia la regla del agotamiento de los recursos internos adquiere, en la práctica, mayor vigor que en el pasado, aunque todavía existe una cifra no

16 Artículo 29.1 del Reglamento de la Comisión.

17 Artículo 26.2 del Reglamento de la Comisión.

18 La Convención Americana sobre Derechos Humanos establece la regla general de agotamiento de los recursos de la jurisdicción interna en el artículo 46.1.a) y las excepciones en el numeral 2 del mismo artículo. 
despreciable de casos en que se aplican las excepciones a ésta. Esta evolución es consecuencia de la reducción de las violaciones masivas y de las reformas a los sistemas judiciales en numerosos países. En conexión con esta materia, es interesante observar cómo se ha diversificado la gama de problemas que analiza la Comisión en el marco de la noción del debido proceso. En este sentido, se ha pasado del tratamiento de problemas de falta de un debido proceso en dictaduras a la revisión de un conjunto de temáticas, como, por ejemplo, el retardo judicial, la libertad provisional, etc. ${ }^{19}$.

Uno de los aspectos referidos al agotamiento de los recursos internos que se ha clarificado en el sistema interamericano en los últimos años se refiere al momento en el cual debe haber ocurrido. Actualmente, para la Comisión y la Corte dicho momento es el de la expedición del pronunciamiento de la Comisión acerca de la admisibilidad de la denuncia. Como ha señalado la Corte, "no debiera confundirse el recibo de una denuncia, que deriva del acto de un denunciante, con la admisión y tramitación de aquella, que se concreta en actos específicos de la propia Comisión, como lo es la resolución que admite la denuncia, en su caso, y la notificación al Estado acerca de ésta" 20 .

También se ha afinado la jurisprudencia en lo referido al tipo de recursos que deben ser agotados. Sobre este particular, como observa Faúndez Ledesma, "[a] diferencia del derecho internacional clásico que admite que los recursos a agotar pueden ser administrativos, arbitrales o judiciales, en el sistema interamericano los recursos que hay que agotar son solamente los de la jurisdicción interna", quedando excluidos de la exigencia de agotamiento los de carácter administrativo o político ${ }^{21}$. Sin embargo, para ciertas hipótesis, la jurisprudencia interamericana ha establecido que corresponde agotar los que denomina "recursos administrativos" cuando ellos sean idóneos para la situación específica de que se trate. Algo similar ocurriría con las vías arbitrales cuando ellas constituyan un modo adecuado para fijar el monto de una indemnización ${ }^{22}$.

Asimismo, la jurisprudencia del sistema interamericano ha tendido a considerar como regla general que sólo es exigible agotar los recursos ordinarios, aunque en ciertas circunstancias también podrían serlo los extraordinarios. De acuerdo a lo señalado por la propia Comisión, "[l]a jurisprudencia del sistema [interamericano] ha establecido que si bien en algunos casos dichos recursos extraordinarios pueden ser adecuados para enfrentar violaciones a los derechos humanos, como norma general los únicos recursos que es necesario agotar son aquellos cuyas funciones, dentro del

19 Paradigmático resulta al respecto el caso de Jorge Alberto Giménez; véase: Informe 12/96 (Argentina), Caso 11.245, $1^{\circ}$ de marzo de 1996. También la Corte ha estudiado diferentes alcances del debido proceso en varios fallos, aunque con pasos atrás y adelante. En el primer sentido (en que predomina una interpretación restrictiva), Corte IDH, Caso Genie Lacayo, sentencia del 29 de enero de 1997; en una dirección más protectora del derecho a un debido proceso, Corte IDH., Caso Castillo Petruzzi y Otros, sentencia de 30 de mayo de 1999, Caso Palamara Iribarne, sentencia de 22 de noviembre de 2005, etc.

20 Corte IDH, Caso Castillo Petruzzi y Otros. Excepciones Preliminares, Sentencia de 4 de septiembre de 1998, párrafo 54. Consúltense también, en idéntico sentido, los siguientes Informes de la Comisión Interamericana de Derechos Humanos: Informe No 44/01, Caso 11.016, Emilio Moisés y Rafael Samuel Gómez Paquiyauri, Perú, 5 de marzo de 2001, párrafo 26; Informe № 52/00, Casos 11.830 y 12.038, Trabajadores Cesados del Congreso de la República, Perú, 15 de junio de 2000, párrafos 19, 20 y 21.

21 FAÚNDEZ LEDESMA H. El agotamiento de los recursos internos en el sistema interamericano de protección de los derechos humanos. Centro de Estudios de Derechos Humanos Universidad Central de Venezuela e Instituto Interamericano de Derechos Humanos, Caracas, 2007; la cita es p. 49. La cursiva es del autor citado. Se ha eliminado una referencia contenida en el texto original.

22 Comisión Interamericana de Derechos Humanos, Informe № 37/05, Inadmisibilidad, Petición 11.433, Benjamín Guerra Duarte, Nicaragua, 9 de marzo de 2005, párrafos 47, 53, 55 y 56. 
sistema jurídico, son apropiadas para brindar protección tendiente a remediar una infracción de determinado derecho legal. En principio se trata de recursos ordinarios, y no extraordinarios" 23 .

De cualquier modo, y sin perjuicio de que la jurisprudencia de la Comisión y la Corte Interamericana ha avanzado en precisar los estándares del agotamiento de los recursos internos, el tipo de casos que llegan actualmente a dichos órganos ha vuelto mucho más compleja la tarea de determinar si este requisito se cumple o no en el asunto específico en su conocimiento.

Atendido el problema de la regla del agotamiento de los recursos internos, históricamente la declaración de admisibilidad de una denuncia por parte de la Comisión no era un asunto que, en la práctica, tuviera mucha relevancia. Como era poco frecuente que los Estados participaran activamente en la tramitación de los casos ante la Comisión, usualmente ésta dejaba la declaración de admisibilidad para la etapa final, resolviendo esta cuestión en la misma resolución en que decidía sobre el fondo.

A partir de los noventa, y en especial en la segunda mitad de dicha década, esta práctica se transformó por completo. En la actualidad, en la gran mayoría de los casos la Comisión emite primero un pronunciamiento acerca de la admisibilidad de la denuncia y solo más adelante (a menudo bastante tiempo después) una decisión sobre el fondo del caso. Esta práctica había sido recogida en una reforma parcial del antiguo Reglamento efectuada en 1996 y el Reglamento de 2001 vino a consolidarla, estableciendo la necesidad de que la Comisión se pronuncie de manera previa y especial acerca de la cuestión de la admisibilidad, salvo que existan circunstancias muy calificadas ${ }^{24}$. Una modificación incorporada al Reglamento en 2006 dispuso que cuando se trate de casos "de gravedad y urgencia o cuando se considere que la vida de una persona o su integridad personal se encuentre en peligro real o inminente [artículo 30.4] [...] la Comisión podrá solicitar al Estado que presente su respuesta y observaciones sobre la admisibilidad y el fondo del asunto" [artículo 30.7]". El artículo 37.3 del mismo Reglamento dispone que "[e]n circunstancias excepcionales, y luego de haber solicitado información a las partes de acuerdo a lo dispuesto en el artículo 30 del presente Reglamento, la Comisión podrá abrir el caso pero diferir el tratamiento de la admisibilidad hasta el debate y decisión sobre el fondo".

Por último, cabe observar que debido a la especial dificultad que representa para la Comisión el pronunciarse acerca de la admisibilidad de algunas denuncias que invocan como excepción la regla del agotamiento de los recursos internos la falta de un debido proceso a nivel interno sin que ello anticipe un pronunciamiento sobre el fondo, en ocasiones ello conduce a la CIDH a emitir una resolución que se refiere de manera conjunta a la admisibilidad y el fondo del caso.

El otro requisito que suele presentar aspectos complejos consiste en las denuncias que se refieran a hechos que caractericen una violación de derechos consagrados en instrumentos internacionales respecto de los cuales la Comisión posea competencia. El examen que efectúa la CIDH en esta etapa de la tramitación es de carácter inicial, por lo cual, la caracterización debe existir prima facie, sin que ello comprometa el pronunciamiento que dicho órgano pueda llegar a emitir sobre el fondo del asunto planteado.

23 Comisión Interamericana de Derechos Humanos, Informe № 51/03, Petición 11.819, Admisibilidad, Christian Daniel Domínguez Domenichetti, Argentina, 24 de octubre de 2003, párrafo 45.

24 La admisibilidad de las peticiones se regula en los artículos 30 a 37 del Reglamento. El artículo 37.3 señala que "en circunstancias excepcionales, y luego de haber solicitado información a las partes de acuerdo a lo dispuesto en el artículo 30 de presente reglamento [que establece un mecanismo contradictorio], la Comisión podrá abrir el caso pero diferir el tratamiento de la admisibilidad hasta el debate y decisión sobre el fondo". 
Sobre este particular, la CIDH ha desarrollado la doctrina denominada de la "cuarta instancia", nomenclatura no muy feliz adoptada del Sistema Europeo de Derechos Humanos. Si bien la Comisión Interamericana ya había recurrido a la doctrina de la "cuarta instancia" a fines de la década de los ochenta, es a partir de mediados de los noventa que ella se consolida ${ }^{25}$. El nombre de cuarta instancia proviene del hecho de que los órganos internacionales de derechos humanos no constituyen una "instancia" en el sentido del Derecho Procesal interno, es decir, que no es suficiente que una persona o grupo de personas se consideren agraviadas por una decisión judicial interna para que automáticamente estén legitimadas para presentar una denuncia admisible a nivel internacional, sino que es necesario que haya una caracterización de una violación a los derechos humanos. Lo de "cuarta" proviene del supuesto de que a nivel interno existirían tres instancias, lo cual usualmente no es el caso, y de allí lo desafortunado de la expresión.

A mi juicio, dos factores han incidido decisivamente para que este requisito haya adquirido una relevancia mucho mayor que en el pasado. Por una parte, los procesos de democratización en el Continente Americano han acarreado un fortalecimiento de los sistemas judiciales internos, que, mirado en términos generales y con variaciones según los países de que se trate, hoy gozan de una mayor independencia e imparcialidad que en el pasado. Por otra, en la medida que se han diversificado de manera muy importante las materias sobre las que versan las denuncias, la Comisión ha debido prestar una atención creciente a la cuestión de la caracterización de los hechos, de manera de apreciar debidamente acaso se cumple o no el requisito ${ }^{26}$.

La CIDH, luego de determinar que la denuncia reúne los elementos para darle tramitación, notificará al Estado al respecto. El Estado deberá presentar sus alegatos dentro del plazo de dos meses contados desde la fecha de transmisión de la petición. Sólo de manera excepcional la Comisión evaluará una solicitud de prórroga de dicho plazo que esté debidamente fundada y que no exceda de tres meses contados a partir de la fecha del envío de la primera solicitud de información al Estado 27 .

La Comisión trasladará la respuesta del Estado al peticionario y verificará si subsisten los motivos que fundamentan la petición. En caso de que considere que han cesado dichos motivos podrá archivar la petición y notificar a las partes de esta decisión. En caso contrario la CIDH preparará un informe de admisibilidad. Hay que señalar que la Comisión puede solicitar información adicional por escrito o mediante el desarrollo de una audiencia antes de preparar el referido informe ${ }^{28}$. Como hemos señalado, de manera excepcional se pueden unir en un solo informe las resoluciones sobre admisibilidad y fondo ${ }^{29}$.

Cuando la Comisión adopta un Informe que dispone la admisibilidad de una petición, se lleva a cabo el registro de la petición y la apertura del $\operatorname{caso}^{30}$, dándose inicio al procedimiento sobre el fondo. Si, en cambio, se resuelve la inadmisibilidad de la petición, concluye la tramitación. Sea

25 Ello ocurre especialmente a partir del Caso Marzioni; véase, Comisión Interamericana de Derechos Humanos, Caso Santiago Marzioni (Argentina), Informe 39/96 (Caso 11.673), 15 de octubre de 1996.

26 La doctrina de la "cuarta instancia" debe distinguirse de la del "margen de apreciación", también originada en el Sistema Europeo y que no ha sido recogida por el Sistema Interamericano, ya que mientras en la primera de ellas se trata de determinar la presencia o no de una caracterización prima facie de una violación a los derechos humanos, en la segunda, admitiéndose que podría haber derechos humanos comprometidos, el órgano internacional considera que los órganos internos se hallan en mejor posición para efectuar un pronunciamiento al respecto (la doctrina del margen de apreciación se aplica o no dependiendo de cuáles sean los derechos involucrados y de otras circunstancias).

27 Artículo 30.3 del Reglamento de la Comisión.

28 Artículo 30.5 y 6 del Reglamento de la Comisión.

29 Artículo 37.3 del Reglamento de la Comisión.

30 Artículo 37.1 y 2 del Reglamento de la Comisión. 
que se decida la admisibilidad o inadmisibilidad de una petición, el informe respectivo se hace público y se incluye en el Informe Anual de la Comisión a la Asamblea General de la OEA.

\section{ii. Procedimiento sobre el fondo}

El procedimiento sobre el fondo se inicia con el registro y apertura del caso ${ }^{31}$. La Comisión fija un plazo de dos meses para que los peticionarios lleven a cabo las observaciones adicionales sobre el fondo ${ }^{32}$. Transcurrido dicho plazo la Comisión trasladará dichas observaciones al Estado con la finalidad de que este presente sus observaciones también dentro de un lapso de dos meses. Posteriormente, las observaciones del Estado son trasladadas al peticionario, quien tendrá oportunidad de presentar nuevas observaciones que a su vez serán trasladadas al Estado.

Se podrán llevar a cabo audiencias si la Comisión así lo decidiera de propia iniciativa o si una de las partes lo solicitara. La CIDH accede a ello, usualmente después de vencidos los plazos de requerimiento y del traslado de información y observaciones a las partes. En estas audiencias se presentan alegaciones, así como, dependiendo del caso, declaraciones de testigos, peritos o pruebas de cualquier carácter.

Dentro del procedimiento sobre el fondo y examen de la petición, la Comisión buscará mediar entre las partes con la finalidad de alcanzar un arreglo amistoso fundado en el respeto de los derechos humanos establecidos en la Convención Americana, la Declaración Americana y otros instrumentos aplicables. Es importante notar que el procedimiento de solución amistosa se inicia y prosigue siempre sobre la base del consentimiento de las partes. Si se logra una solución amistosa, la Comisión aprueba un informe de la solución lograda que trasmite a las partes y se hace público. La Comisión verifica, antes de la publicación del informe, si la víctima de la presunta violación o sus derechohabientes han dado su consentimiento en el acuerdo de solución amistosa. En caso de no lograr un acuerdo de solución amistosa entre las partes, la Comisión proseguirá el trámite de la petición ${ }^{33}$.

El acuerdo amistoso debe ser acorde con las normas de derecho internacional de los derechos humanos, tener por objeto reparar los perjuicios causados a la víctimas y sus familiares, y establecer una serie de medidas que deberá implementar el Estado responsable con la finalidad evitar que hechos similares vuelvan a ocurrir. Este acuerdo tiene carácter vinculante y será la propia Comisión la encargada de supervisar su cumplimiento.

Desde comienzos de los años noventa del siglo pasado la Comisión Interamericana de Derechos Humanos ha venido haciendo un uso creciente del mecanismo de solución amistosa. Algunos casos argentinos fueron los que marcaron el rumbo en la línea de emplear este mecanismo. Éstos fueron los casos acumulados de Miguel Vaca Narvaja (derechohabiente), Guillermo Alberto Birt y otros, en relación violaciones a sus derechos humanos ocurridas durante la dictadura ${ }^{34}$, y el del periodista Horacio Verbitsky, quien había sido condenado por el delito de desacato, que en la legislación de ese país consistía en un delito agravado de injurias contra ciertas autoridades

\footnotetext{
31 Artículo 37 del Reglamento de la Comisión.

32 Artículo 38.1 del Reglamento de la Comisión.

33 Artículo 41 del Reglamento de la Comisión.

34 Comisión Interamericana de Derechos Humanos, Informe Anual 1992-93, Informe № 1/93, sobre solución amistosa respecto de los casos 10.288, 10.310, 10.436, 10.49610 .631 y 10.771.
} 
públicas $^{35}$. En los casos acumulados, Argentina pagó indemnizaciones por los abusos cometidos y en el de Verbitsky la figura penal del desacato fue derogada ${ }^{36}$.

Ambas soluciones amistosas tuvieron un impacto que fue más allá de los casos específicos. El arreglo con las víctimas de la dictadura en el conjunto de casos acumulados ante la Comisión promovió en Argentina el diseño de una política de indemnizaciones en la materia. En cuanto al desacato, la derogación de esta figura penal en Argentina fue seguida por un Informe de la Comisión Interamericana sobre Leyes de Desacato ${ }^{37}$. Este Informe, de carácter temático y no referido a un país en particular, establecía que dichas leyes eran incompatibles con la garantía de la libertad de expresión consagrada en la Convención Americana.

El fortalecimiento de las soluciones amistosas fue posteriormente reforzado por la Corte Interamericana. Ésta había sostenido en el caso Velásquez Rodríguez que no era obligatorio para la Comisión ofrecer una solución amistosa a las partes en todos los casos individuales de los que conociera, especialmente en un contexto como el hondureño respecto de Velásquez, en que ni siquiera se había emprendido una investigación interna para esclarecer la desaparición forzada $^{38}$. Pero en el caso Caballero Delgado y Santana contra Colombia, ya en los noventa, la Corte consideró que la sola naturaleza de la violación (también como en Velásquez se trataba de la desaparición forzada de personas) no servía como fundamento suficiente para no ofrecer a las partes una solución amistosa, considerando que Colombia, a diferencia de Honduras en el caso Velásquez, sí había realizado una investigación interna e intentado colaborar para solucionar la violación. No obstante, la Corte añadió que la obligación de la Comisión en los casos en que las partes demostraran voluntad de cooperación, se satisfacía con iniciar este trámite si una de la partes así lo solicitaba ${ }^{39}$.

En rigor, la Comisión fue más allá de lo planteado por la Corte, ya que comenzó a hacer un uso sistemático del mecanismo de solución amistosa, tomando la iniciativa en cada caso al ponerse a disposición de las partes para tales efectos. Desde entonces muchos casos de importancia han sido solucionados por esta vía.

\section{iii. Decisión sobre el fondo y sometimiento del caso a la Corte Interamericana}

La Comisión mediante la decisión sobre el fondo podrá determinar si considera que el Estado denunciado es responsable de violaciones de derechos humanos y (a) elaborar un informe preliminar con recomendaciones para el Estado responsable, (b) o concluir que no ha podido constatar violaciones de derechos humanos o que estas fueron reparadas oportunamente. En este último

35 Véase Comisión Interamericana de Derechos Humanos, Informe Anual 1994, Informe 22/94, Caso 11.102.

36 Véase sobre las soluciones amistosas argentinas que catalizaron el fortalecimiento de este mecanismo, CARDOZO J. La solución amistosa ante la Corte. En: MÉNDEZ J. y COX F. (eds.). El Futuro del Sistema Interamericano de Protección de los Derechos Humanos. Instituto Interamericano de Derechos Humanos, San José de Costa Rica, 1998, pp. $391-409$. El autor del artículo era un funcionario del gobierno de ese país que intervino en varias soluciones amistosas; a pesar de su título, el trabajo se refiere también a soluciones amistosas en la Comisión.

37 Publicado en el Informe Anual de la Comisión Interamericana de Derechos Humanos 1994, pp. 209 ss.

38 Corte IDH., Caso Velásquez Rodríguez, Excepciones Preliminares, Sentencia de 26 de junio de 1987, pp. 19-21. Sobre la solución amistosa de casos en el Sistema Interamericano, puede consultarse STANDAERT P. The Friendly Settlement of Human Rights Abuses in the Americas. Duke Journal of Comparative and International Law. Vol. 9, pp. 519-542 (Primavera 1999).

39 Corte IDH., Caso Caballero Delgado y Santana, Excepciones Preliminares, sentencia de 21 de enero de 1994. Véase especialmente pp. 526-27. 
caso la Comisión transmite el informe a las partes, el que será posteriormente publicado e incluido en el Informe Anual de la Comisión a la Asamblea General de la OEA ${ }^{40}$.

Si la Comisión concluye en su decisión sobre el fondo que un Estado parte de la OEA que no ha suscrito la Convención es responsable de violaciones de derechos humanos le otorgará un plazo para que implemente las recomendaciones dictadas. En caso de que el Estado responsable no parte no diera cumplimiento al contenido de la decisión, la Comisión está facultada para publicarla, ya sea en su Informe Anual o mediante otro mecanismo. La CIDH le dará seguimiento al caso mientras la decisión recaída en este no haya sido acatada.

Distinto es el procedimiento cuando la Comisión emite una resolución en la que establece que un Estado parte de la Convención es responsable de los cargos hechos en su contra. En esta situación, la CIDH notifica al Estado de su informe preliminar con las recomendaciones y observaciones pertinentes, y le otorga un plazo para que informe sobre las medidas adoptadas con la finalidad de cumplir las recomendaciones ${ }^{41}$.

La Comisión deberá notificar al peticionario de la adopción del informe y su transmisión al Estado y le brindará la oportunidad de presentar en el plazo de un mes su posición respecto del sometimiento del caso a la Corte ${ }^{42}$. El peticionario que tuviera interés en que el caso sea sometido a la Corte deberá informar de la posición de la víctima o sus familiares, en caso de que fueran distintos del peticionario, los fundamentos del caso, la prueba documental, testimonial y pericial disponible y sus pretensiones en materia de reparaciones y $\operatorname{costas}^{43}$. No obstante, la decisión final sobre el sometimiento del caso ante la Corte la tiene la Comisión.

En el caso de que transcurra el plazo determinado por la Comisión sin que el Estado informe de las medidas adoptadas para dar cumplimiento a las recomendaciones y considere que las ha incumplido, la CIDH resolverá si somete o no el caso ante la Corte ${ }^{44}$. Esto, claro, en el supuesto de que se trate de un Estado que haya reconocido la jurisdicción contenciosa del tribunal interamericano. La Comisión puede asimismo conceder prórrogas al Estado respectivo cuando observe que se producen avances relevantes en el cumplimiento de la resolución dictada.

Conforme a la Convención Americana, la Comisión y los Estados son los únicos facultados para presentar casos contenciosos ante la Corte, pero en la práctica los Estados no han hecho uso de esta facultad, salvo en una oportunidad en que Costa Rica sometió un caso a conocimiento de la Corte sin agotar la tramitación en la Comisión, lo cual fue desestimado por el tribunal por improcedente ${ }^{45}$.

Desde los noventa la Comisión empezó a enviar casos con mayor regularidad a la Corte, remitiendo varias decenas de ellos. En este contexto de aumento del número de casos, se intensificaron las críticas por la ausencia de criterios para determinar el envío o no de un caso por parte de la

\footnotetext{
40 Artículo 43.1 y 2 del Reglamento de la Comisión.

41 Artículo 43.2 del Reglamento de la Comisión.

42 Esta es la solución práctica a que ha arribado la Comisión para hacer efectivos los parámetros establecidos por la Corte Interamericana en la Opinión Consultiva 13. En dicha opinión, el tribunal interpretó el artículo 50 de la Convención Americana en el sentido de que prohíbe a la Comisión dar a conocer a los peticionarios el contenido del mencionado informe. Anteriormente la Comisión entendía que el artículo 50, al señalar que sólo se daría traslado a los Estados interesados se refería sólo a los casos de denuncias interestatales. Véase, Corte IDH, Ciertas atribuciones de la Comisión Interamericana de Derechos Humanos, Opinión Consultiva № 13, 16 de julio de 1993. La práctica actual de la Comisión aparece recogida en el artículo 43.3 de su Reglamento.

43 Artículo 43.3 del Reglamento de la Comisión.

44 Artículo 44.1 del Reglamento de la Comisión.

45 Véase, Corte IDH., Asunto de Viviana Gallardo y otras, Nº G 101/81.
} 
Comisión a la Corte ${ }^{46}$. El Reglamento de 2001 de la CIDH estableció dichos criterios. Así, señala como regla general que cuando un Estado no haya cumplido la resolución de la CIDH, ésta enviará el caso a la Corte.

El Reglamento añade que para tales efectos "se considerará fundamentalmente la obtención de justicia en el caso particular", para cuya determinación se atenderá, entre otros factores, a "a) la posición del peticionario; b) la naturaleza y gravedad de la violación; c) la necesidad de desarrollar o aclarar la jurisprudencia del Sistema; d) El eventual efecto de la decisión en los ordenamientos jurídicos de los Estados Miembros; y e) La calidad de la prueba disponible" (artículo 44.2).

La Comisión deberá notificar a las partes de su decisión de someter el caso ante la Corte e informar al peticionario de todos los elementos necesarios para la elaboración de la demanda ${ }^{47}$.

Conforme con los criterios arriba señalados, la Comisión, a pesar de que el Estado en cuestión no haya adoptado medidas para dar cumplimiento a sus recomendaciones, puede decidir mediante una decisión fundada de la mayoría absoluta de sus miembros, no someter el caso ante la jurisdicción de la Corte ${ }^{48}$. En este caso la Comisión aprobará y publicará un informe definitivo que contenga sus conclusiones y recomendaciones. Posteriormente le dará seguimiento al cumplimiento del mismo, pudiendo incluso realizar audiencias públicas para tales efectos. Estos últimos pasos -aprobación y publicación del informe definitivo y seguimiento del mismo- se verifican cuando el respectivo Estado no haya reconocido la jurisdicción contenciosa de la Corte Interamericana.

\section{Las prioridades de la Comisión}

Dadas sus múltiples funciones, los desafíos de gran envergadura que siempre ha confrontado y los contextos muy variados en los que ha debido operar, la Comisión Interamericana de Derechos Humanos ha reevaluado permanentemente sus prioridades. La sociedad civil y los Estados también han tomado parte de las iniciativas de evaluación, a veces en la dirección del fortalecimiento de la CIDH y en otras ocasiones en la dirección opuesta.

En un comienzo, la prioridad de la Comisión consistió en la elaboración de Informes sobre Países, en lo posible mediante la realización de visitas in loco. Al mismo tiempo, la CIDH planteó a los órganos políticos de la OEA desde su primer período de sesiones y durante varios años que se le reconociera el poder de conocer de casos específicos, reconocimiento que obtuvo en 1965 . Sin embargo, por los cambios de contexto que hemos expuesto en este trabajo, el sistema de casos de la Comisión recién se consolidó a partir de la década de los 90 y hasta nuestros días. También hemos descrito cómo en el contexto de los procesos de democratización algunos Estados señalaron que la CIDH debía concentrarse prioritariamente en labores de promoción, dejando de lado sus Informes sobre Países (por ser una supuesta rémora de la época de las dictaduras). Asimismo, hemos revisado de qué manera la Comisión Interamericana ha venido desarrollando un trabajo temático a través de un sistema de relatorías desde la década pasada, efectuando visitas a tal efecto y publicando Informes.

46 Cabe recordar aquí que en esta materia la antigua Comisión Europea de Derechos Humanos tampoco disponía de criterios para el envío de casos a la Corte. Sin embargo, bajo la modalidad antigua del Sistema Europeo todos los casos que decidía la Comisión eran remitidos a otro órgano, ya fuera la Corte Europea de Derechos Humanos o al Comité de Ministros. Véase, MÉNDEZ J. Una Aproximación Crítica a la Interpretación Vigente de los Artículos 50 y 51 de la Convención. En: MÉNDEZ J. y COX F. (eds.). El Futuro del Sistema Interamericano de Protección de los Derechos Humanos, Instituto Interamericano de Derechos Humanos, San José de Costa Rica, 1998, pp. 241-260; la referencia es de pp. 254-255.

47 Artículo 71 del Reglamento de la Comisión.

48 Artículo 44.1 del Reglamento de la Comisión. 
Otra alternativa que se ha planteado como una posible función prioritaria es la de prestar asistencia técnica a los Estados en materia de derechos humanos. Esto, en cierta medida, se asemejaría a lo que realiza Naciones Unidas al respecto. Por una parte, cabe observar que en algunas oportunidades ha sido la Asamblea General de la OEA -que, claro está, reúne al conjunto de Estados de dicha organización- la que le ha pedido asistencia técnica a la Comisión. Por ejemplo, en los últimos años ello se le planteó respecto de las acciones afirmativas (con miras a considerar su relevancia en el Proyecto de Convención Interamericana contra el Racismo, la Intolerancia y la Xenofobia), así como para la elaboración de un conjunto de "Lineamientos en materia de derechos económicos, sociales y culturales", de modo que sirvan como base para el trabajo a ser realizado por el futuro órgano creado por el Protocolo de San Salvador sobre la materia. Por otra parte, se ha planteado la posibilidad de que la Comisión fortalezca este tipo de labor en relación con Estados específicos. La CIDH ya lleva a cabo esta clase de iniciativas, aunque de manera acotada, especialmente por medio de sus relatorías temáticas, especialmente a través de la referida a libertad de expresión.

El problema que representaría un fortalecimiento significativo de estas iniciativas de asesoría técnica, además de implicar reducir recursos humanos y financieros para otras áreas, es que, de alguna manera, llevaría a menudo a que la Comisión evaluara anticipadamente, es decir, prejuzgara, sobre asuntos que más tarde pueden llegar a su conocimiento por la vía de su sistema de casos.

En la actualidad la Comisión desarrolla como función prioritaria su sistema de casos. Asimismo, mantiene como aspecto prioritario de sus labores la preparación y publicación de Informes sobre Países, precedidas por visitas in loco cuando los Estados respectivos así lo autorizan. Aunque la $\mathrm{CIDH}$ reconoce la relevancia de sus demás tareas, su centralidad no es la misma que las dos antes mencionadas. La justificación para ello emana del carácter único que posee el sistema de casos ante la Comisión como mecanismo de acceso general para la presentación de denuncias, de tal modo que las víctimas de violaciones puedan llevar sus alegaciones ante la esfera interamericana. En cuanto a los Informes sobre Países, ellos son prioritarios como una vía para seguir de cerca aquellas situaciones que a juicio de la Comisión resultan merecedoras de especial atención. Por lo que se refiere a la visitas in loco, además de servir para recabar información para la elaboración de Informes, ellas contribuyen de manera muy importante a dotar de visibilidad al trabajo de la $\mathrm{CIDH}$ en el Continente.

Las demás tareas de la Comisión también poseen relevancia, pero, como hemos destacado, no son únicas de esta institución, puesto que iniciativas de naturaleza análoga son llevadas a cabo por los propios Estados, por instituciones académicas y por la sociedad civil. Es cierto que cuando es la propia Comisión la que emprende tales labores (como informes temáticos o actividades de promoción) ellas tienen un sentido que no es exactamente el mismo que si las llevan a cabo algunos de los tres tipos de entidades señaladas, pero la diferencia no es de tal grado como para justificar disminuir la atención al sistema de casos, los Informes sobre Países o las visitas in loco.

\section{La autonomía funcional de la Comisión}

Un elemento clave para el rápido potenciamiento que experimentó la Comisión desde el inicio de sus labores fue la calidad de expertos independientes que sus miembros poseen. Sin embargo, a pesar de que los comisionados tienen esa característica, el personal administrativo continúa dependiendo, desde el punto de vista jurídico, de la Secretaría General de la OEA. Esto significa que es el Secretario General quien designa a los funcionarios de la Comisión, incluyendo no solo a sus abogados sino también al Secretario Ejecutivo de la Comisión. Como es obvio, esto limita a la $\mathrm{CIDH}$, pues no puede seleccionar a su personal conforme a sus propios criterios y prioridades. El problema es aun más patente si se considera que los comisionados no ejercen sus 
labores a tiempo completo, sino que sesionan durante algunas semanas, en algunos momentos de cada año. Por lo mismo, el personal de la Secretaría de la Comisión es clave para el desarrollo cotidiano de sus actividades.

Históricamente se había recurrido a diversas fórmulas para el reemplazo de los funcionarios. Como éstos, en rigor, son funcionarios de la OEA, a veces (mediante una decisión del Secretario General de la organización, claro está) se recurría a su traslado a otros departamentos de la OEA, e incluso al "enroque" de funcionarios de la Comisión por otros que se desempeñaban en otras secciones de la OEA. En la primera mitad de la década de los noventa este asunto hizo crisis. Los comisionados consideraron necesario reemplazar a la Secretaria Ejecutiva de la época. Como la decisión no dependía de ellos, pusieron su intención en conocimiento del Secretario General de la OEA. Durante varios meses se vivió una situación completamente anómala y perjudicial para el Sistema, en que la Secretaria Ejecutiva no contaba con la confianza de sus superiores inmediatos pero seguía ejerciendo sus funciones. Uno de los miembros de la Comisión, el profesor Michael Reisman, incluso renunció por este motivo ${ }^{49}$. Finalmente, el Secretario General de la OEA (por ese entonces César Gaviria) accedió a la petición de la Comisión y dispuso el reemplazo de la Secretaria Ejecutiva. Así, la "impasse" puntual fue solucionada, pero sin que las reglas que regulan esta materia fueran modificadas.

En términos jurídicos, la Comisión carece hasta la actualidad de autonomía para designar a su personal. No obstante ello, en la práctica, tanto bajo el mandato de César Gaviria como Secretario General de la OEA, como en el del actual Secretario General, José Miguel Insulza, ha sido la propia Comisión la que ha nombrado a su personal, sin que el Secretario General haya impugnado estas designaciones, por lo que en la realidad la $\mathrm{CIDH}$ ha gozado en los últimos años de un ámbito mucho mayor de autonomía funcional.

Sin embargo, en la medida en que dicha autonomía funcional no se consagre jurídicamente la situación continuará siendo precaria, ya que no existe ningún obstáculo legal para que la práctica de los últimos años pueda ser revertida.

\section{A modo de conclusión: el nivel de impacto de la CIDH}

Desde que fuera creada hace 50 años, la Comisión Interamericana de Derechos Humanos ha desempeñado un papel de suma importancia en la protección de tales derechos en el Continente Americano. Desde un comienzo, con medios muy limitados, dicho organismo ha llevado adelante esfuerzos significativos en tal dirección.

Durante sus primeras tres décadas de trabajo, casi la totalidad de las iniciativas de la CIDH se concentraron en las violaciones cometidas de manera masiva y sistemática por regímenes dictatoriales. Sin embargo, en la medida en que se ha evolucionado hacia sistemas democráticos de gobierno, la Comisión ha diversificado sus tareas, así como el tipo de materias a las que se aboca, labor que no ha estado exenta de obstáculos, pero cuyo balance general es positivo.

La CIDH posee una variedad de funciones, que incluyen, entre otras, la tramitación y decisión de casos específicos y la publicación de informes temáticos y sobre países. Mediante tales mecanismos la Comisión procura adaptar sus labores a tiempos cambiantes, con el objetivo de hacer su trabajo lo más eficaz posible.

49 Consúltese, GONZÁLEZ F., RODRíGUEZ D. Y SALAZAR K. Derechos Humanos y Organización de Estados Americanos 1995-1996. Revista de la Comisión Internacional de Juristas. № 56, pp. 25-39. 
Sin embargo, como suele suceder con los órganos internacionales de derechos humanos, determinar el nivel de su impacto sólo puede ser hecho de manera estimativa. Ello porque la eficacia de los informes y resoluciones de dichos órganos a menudo es difusa, en el sentido de que los Estados no siempre reconocen que la labor de tales órganos haya incidido en los cambios de sus normativas y prácticas a nivel interno.

En el caso de la Comisión Interamericana, como hemos revisado a propósito de sus distintas funciones, su nivel de impacto en determinados contextos ha sido significativo, contribuyendo a ello factores relevantes como la visibilidad pública que dicho organismo ha poseído desde sus inicios y el hecho de que los comisionados(as) operen de manera autónoma, no dependiente de los Estados de los cuales son nacionales. No obstante, en otros momentos o respecto de determinados Estados su impacto ha sido débil. El énfasis que la Comisión ha ido poniendo en distintas etapas de su historia en unas funciones $u$ otras ha obedecido justamente a la necesidad de hacer lo más eficaz posible sus labores.

En relación con las dos funciones que la Comisión ha privilegiado históricamente, esto es, los Informes sobre países y el sistema de casos, cabe señalar respecto de los primeros que ellos han contribuido para que la comunidad internacional tome conocimiento de la situación de los derechos humanos en determinados Estados y para que se emprendan transformaciones a nivel interno. Sin embargo, dado el amplio espectro de temas que se abarcan en los Informes sobre Países, invariablemente su grado de eficacia ha sido parcial. En lo concerniente al sistema de casos, ha sido evidente su mayor eficacia a partir de la década de los noventa, aunque el grado en que ello ha ocurrido no ha sido homogéneo, variando según los Estados y los Gobiernos de turno. También ha sido limitado el papel que han desempeñado los órganos políticos de la OEA como garantes colectivos de la eficacia del Sistema Interamericano de Derechos Humanos. De cualquier modo, es claro que se ha ido consolidando una jurisprudencia interamericana, tarea en la cual han tomado parte la Comisión y a Corte y que ella ha ido adquiriendo creciente influencia a nivel interno de los Estados, lo cual se revela en la adopción de determinadas políticas públicas y en la jurisprudencia interna.

El trabajo temático y las labores de promoción, por su parte, producen un impacto transversal en la medida en que usualmente no se refieren a un país específico. En conexión con estas funciones, deben resaltarse las iniciativas de interacción que se producen entre la Comisión Interamericana y las autoridades estatales, así como con las organizaciones de la sociedad civil, lo cual redunda, dependiendo de los contextos y de las circunstancias, en reformas legislativas internas, recepción de los estándares interamericanos a nivel judicial de los Estados, creciente conciencia de la sociedad civil acerca del alcance de sus derechos y de las formas de hacerlos efectivos, entre otras consecuencias. 
